\title{
DETERMINATION OF THE ABILITY TO MEASURE TRACES OF WATER IN DEHYDRATED RESIDUES OF WASTE WATER BY IR DIFFUSE REFLECTANCE SPECTRA
}

\begin{abstract}
S. V. Pratsenka, ${ }^{a^{*}}$ E. S. Voropai, ${ }^{a}$ and V. G. Belkin ${ }^{b}$
UDC 543.424.4

Rapid measurement of the moisture content of dehydrated residues is a critical problem, the solution of which will increase the efficiency of treatment facilities and optimize the process of applying flocculants. The ability to determine the moisture content of dehydrated residues using a meter operating on the IR reflectance principle was confirmed experimentally. The most suitable interference filters were selected based on an analysis of the obtained diffuse reflectance spectrum of the dehydrated residue in the range 1.0-2.7 $\mu \mathrm{m}$. Calibration curves were constructed and compared for each filter set. A measuring filter with a transmittance maximum at $1.19 \mu \mathrm{m}$ and a reference filter with a maximum at $1.3 \mu \mathrm{m}$ gave the best agreement with the laboratory measurements.
\end{abstract}

Keywords: diffuse reflection, infrared spectroscopy, moisture determination, dehydrated residue.

Water purification is one of the most important processes in the engineering infrastructure of urbanized areas. The process includes several stages, a key one of which is dehydration of the residue [1]. The main goal of this technical drying is to increase the content of dry matter in the residue using a centrifuge or belt presses. The dehydrated residue is a water-purification product resulting from the action of physical and chemical factors. A costly flocculant that binds particles is used to increase the dehydration efficiency. Its amount is periodically adjusted depending on the moisture content of the analyzed material.

Common moisture determination methods [2] do not allow the addition of flocculant to be adjusted in real time because of the length of the analyses. This decreases the dehydration efficiency and entails additional consumption during production. Therefore, determination of moisture in the dehydrated residue by rapid methods with uncertainties comparable to those of laboratory equipment is a critical problem [3]. Solution of this problem would allow the amount of added flocculant to be automated, thereby making the purification facilities more affordable.

Aquar-Systems Ltd. together with Laser Physics and Spectroscopy Section of the BGU Physics Department are leading the development and implementation in the Republic of Belarus of a meter operating on the near-IR reflectance principle $[4,5]$. The features of this contact-free method include simple sample preparation, high measurement rate, and repeatable results. Therefore, the Aquar-1108 meter operating on the radiation reflectance principle was tested in the residue treatment unit of the Minsk purification station (RTU MPS). The main goal was to confirm experimentally the ability to measure the moisture of the dehydrated residue using IR diffuse reflectance.

It is noteworthy that the dehydrated residue had several features that complicated the spectroscopic investigations. Therefore, it was decided to obtain the diffuse reflectance spectrum in the range 1-2.7 $\mu \mathrm{m}$ for one sample and to use these data to select a set of interference filters for the experimental confirmation. The water absorption spectrum in this range consists of combination bands of standard vibrations at $87,370,6896$, and $5181 \mathrm{~cm}^{-1}$. Absorption at 1.93 or $1.45 \mu \mathrm{m}$ was used as the analytical wavelength in most instances for samples with simple compositions. However, the measurements decreased in repeatability and in several instances became impossible if materials consisting of a large number of uncontrolled components were analyzed. In such instances, a portion of the spectrum that was less affected by the extraneous components was sought.

Figure 1 shows the diffuse reflectance spectrum of a dehydrated residue with $79.3 \%$ moisture that was obtained on a MATRIX-1 FTIR spectrometer. Sets of interference filters that could be used as the measuring and reference filters were selected by analyzing this spectrum. Thus, three sets of interference filters were used in the tests (Table 1).

*To whom correspondence should be addressed.

${ }^{a}$ Belarusian State University, 4 Nezavisimost' Ave., Minsk, 220030, Belarus; email: stas-p0@rambler.ru; voropay@ bsu.by; ${ }^{b}$ Aquar-Systems Ltd., Minsk, 220007, Belarus; email: vgb1240@gmail.com. Translated from Zhurnal Prikladnoi Spektroskopii, Vol. 84, No. 6, pp. 1009-1012, November-December, 2017. Original article submitted June 21, 2017. 


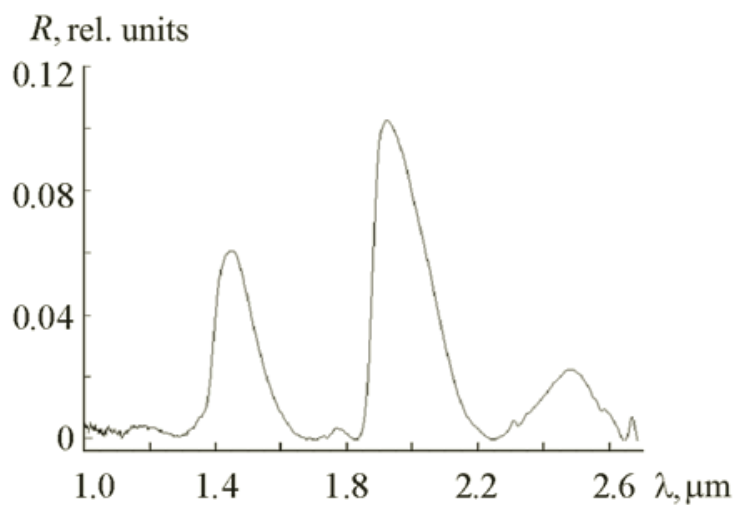

Fig. 1. Diffuse reflectance spectrum of dehydrated residue with $79.3 \%$ moisture in the range $1-2.7 \mu \mathrm{m}$.

TABLE 1. Interference Filter Sets

\begin{tabular}{|c|c|c|}
\hline Set & Analytical wavelength, $\mu \mathrm{m}$ & Reference wavelength, $\mu \mathrm{m}$ \\
\hline 1 & 1.93 & 1.7 \\
2 & 1.45 & 1.3 \\
3 & 1.19 & 1.3 \\
\hline
\end{tabular}

The moisture content of each sample was determined in the laboratory using thermogravimetry on a Sartorius MA45 balance with the heater at $105^{\circ} \mathrm{C}$. According to the specifications, the uncertainty of the moisture measurement by thermogravimetry was $\pm 0.05 \%$ for a sample of mass $>5 \mathrm{~g}$. The average duration of a single measurement varied from 40 to $65 \mathrm{~min}$. The problem was complicated by the fact that the meter received a signal that contained the total information about all absorption bands within the half-width of the interference filter at the analytical wavelength. In several instances, this effect was insignificant and enabled the received signal to be used for calibration without several mathematical transformations.

The signal at the analytical wavelength was recorded during the calibration of the moisture meter for each set of interference filters. The results were used to determine the type of calibration curve and to derive the determination coefficient. The reflectance moisture meter was installed next to the storage bunker, where the dehydrated residue from the three dehydration systems was mixed the most. Figure 2 shows the optical diagram of the Aquar-1108 IR reflectance moisture meter. Such a setup ensured reliability and indifference to external influences, in particular, vibrations.

Figure 3 shows calibration curves for the various analytical and reference wavelengths. The experiment took eight months. An analysis of the obtained calibration curves with various sets of interference filters (Fig. 3) led to the conclusion that the moisture content of the dehydrated residue could be measured most conveniently at analytical wavelength $1.19 \mu \mathrm{m}$ and reference wavelength $1.3 \mu \mathrm{m}$. This was explained primarily by the decreased effects of the dehydrated residue components on the resulting diffuse reflectance spectrum.

Figure $3 \mathrm{a}$ and $3 \mathrm{~b}$ illustrate the uncontrolled effects of absorption by extraneous components that was also detected by the photomultiplier. This complicated considerably the moisture determination of the dehydrated residue at analytical wavelengths 1.45 and $1.93 \mu \mathrm{m}$. Figure $3 \mathrm{c}$ shows measurements at analytical wavelength $1.19 \mu \mathrm{m}$. The determination coefficient increased relative to the two preceding results because the influence of the extraneous components decreased. This enabled this spectral portion to be used to determine the moisture content of the dehydrated residue.

Thus, it was shown that diffuse reflectance spectra could be used to determine the moisture content of a dehydrated residue. The amount of added flocculant could be adjusted continuously by continuation of the investigations and subsequent implementation of the reflectance moisture meter into the technical residue dehydration process, thereby increasing the operating efficiency of the facility. The optimum sets of interference filters used in the reflectance meter were determined from the spectroscopic tests of a dehydrated residue with $79.3 \%$ moisture content. The experiment showed that the results were most repeatable if the analytical filter had a transmission maximum at $1.19 \mu \mathrm{m}$ with a reference filter at $1.3 \mu \mathrm{m}$. 


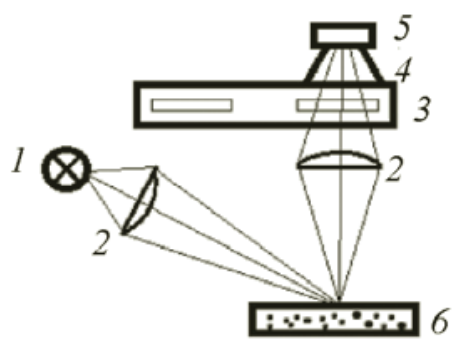

Fig. 2. Optical diagram for measuring sample moisture: 1) emitter, 2) lenses, 3) modulator with interference filters, 4) conical trap, 5) photomultiplier, 6) sample.
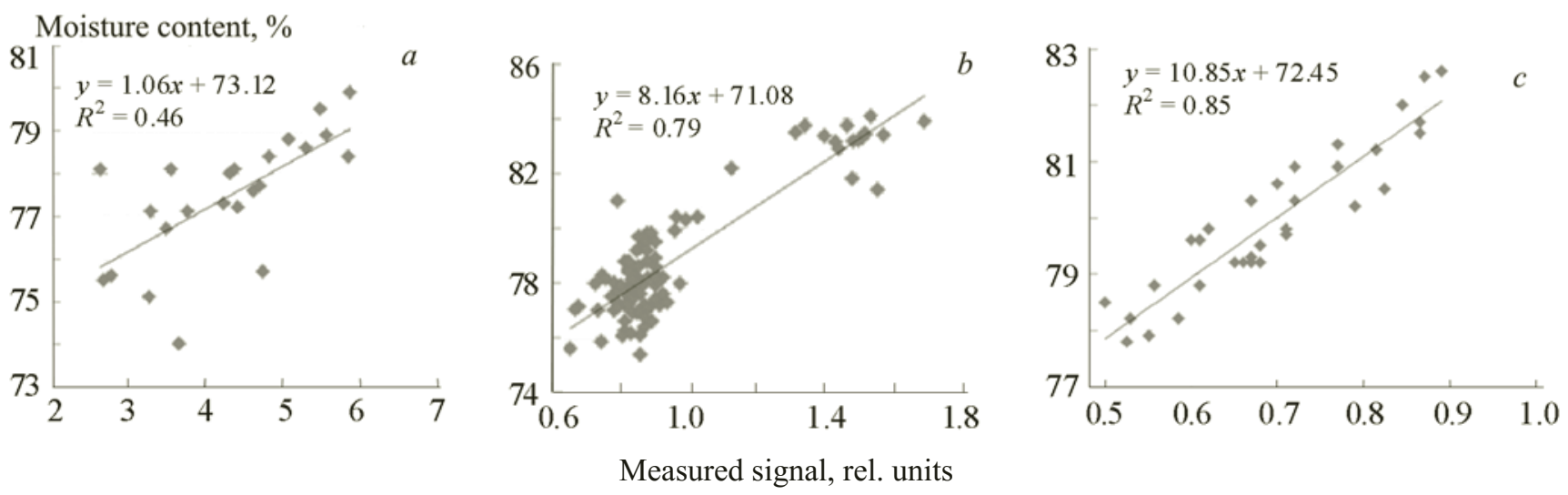

Fig. 3. Calibration curves for determining the moisture content in dehydrated residue in the ranges: a) $74-80 \%$ at analytical wavelength $1.93 \mu \mathrm{m}$ and reference $1.7 \mu \mathrm{m}$; b) $75-84 \%$ at analytical wavelength $1.45 \mu \mathrm{m}$ and reference $1.3 \mu \mathrm{m}$; c) $78-83 \%$ at analytical wavelength $1.19 \mu \mathrm{m}$ and reference $1.3 \mu \mathrm{m}$.

\section{REFERENCES}

1. E. S. Voropai, in: Proc. II Int. Sci-Tech. Internet Conf. "Resource Conservation and Energy Efficiency of the Engineering Infrastructure of Urbanized Areas and Industrial Facilities" [in Russian], February 2-27, 2016, Kharkov, KhNUGKh im. A. N. Beketovich (2016), pp. 42-44.

2. V. P. Krishchenko, Near Infrared Spectroscopy [in Russian], Kronn-press, Moscow (1997).

3. M. Mukhutdinov and E. S. Musaev, Optical Methods and Devices for Moisture Monitoring [in Russian], Energoatomizdat, Moscow (1986).

4. V. G. Belkin and S. V. Protsenko, Vestn. Beloruss. Gos. Univ., Ser. 1: Fiz. Mat. Inf., No. 3, 22-25 (2014).

5. E. S. Voropai, V. G. Belkin, S. V. Protsenko, K. V. Govorun, and E. A. Kolova, Vestn. Beloruss. Gos. Univ., Ser. 1: Fiz. Mat. Inf., No. 1, 16-20 (2016). 